\title{
Editorial
}

\section{New directions for JCOM}

\author{
ABSTRACT: A new editorial board is guiding JCOM through a period of change \\ and here opens out the discussion on what JCOM has become and what it could \\ or should become in the future. The journal's readers are invited to make their \\ contributions.
}

With this issue, JCOM initiates a process of change that is aimed at securing the journal's future and strengthening its contribution to the international science communication communities. Over the coming months, JCOM will develop new structures of governance and new modes of publishing. Our purpose is to make the journal more responsive to the needs of science communication communities, more transparent in its operations, more open to debate and discussion on issues in science communication, and more open to innovation and experimentation in investigating those issues. We invite the journal's readers to join the discussion on improving JCOM and making it even more relevant to researchers, educators and practitioners in science communication.

JCOM was founded in 2002 and has established for itself a certain reputation among various science communication communities. The journal's hybrid character — in part academic, in part professional — represents both a strength and a weakness. On the one hand, the journal's accessibility has attracted professionals who might otherwise not have considered theoretical reflections and formal studies useful for their work. The open access policy and the publication of texts in both English and the authors' primary language have enlarged the audience geographically too, notably well beyond Europe. On the other hand, JCOM may not have achieved the authoritative status it aspires to, and which its selectivity and quality criteria are aimed at reaching.

JCOM's hybridity reflects, in some way, the status of the science communication field; scholars have struggled to establish it as a defined, recognized area of research. This journal has published important reflections and analyses on this topic. But it remains a challenge to retain a perspective on science communication that acknowledges and fosters relations between research and practice. For JCOM, this challenge also represents an opportunity for stimulating research and reflection.

Our recent survey indicated the broad geographical and occupational spread of the journal's readers and, unsurprisingly, the wide range of views on the journal's achievements and ambitions. We are analyzing the results in more detail but we can note that the survey respondents rated JCOM papers most highly for interest and originality. They indicated their own interest in a spread of topics, ranking public perception of S\&T highest. They responded to the open question on changes they 
wished for JCOM in very varied ways, but there was an emphasis on exploring various intellectual perspectives, including through discussion and debate.

JCOM's stability has been secured, at least for the near future, by SISSA Medialab taking responsibility, as publisher, for financial and management matters. Medialab publishes several high-impact journals in the physical sciences and other fields. The publisher has asked the five signatories to this editorial to be an interim editorial board, overseeing the transition to a new JCOM. This editorial group is responsible for the editorial direction of the journal in this transition period. A new editor-in-chief and advisory board will be appointed in the coming months.

Several members of the interim editorial board expressed their hopes for JCOM in the most recent issue (March 2013). Their priorities included: maintain curiosity for research and comments from people living in different cultural, social and economic context, bringing a rich diversity of the discussions; make JCOM the place where we can identify and analyse actions and studies on how to make science a form of empowerment instead of an instrument of exclusion; amplify the instruments and the methods for readers to interact; increase themed groups of Comments, ensure diverse viewpoints are represented and facilitate contributions from readers.

This discussion continues and we wish to involve readers in it. We have already undertaken the survey mentioned above. We now ask readers to propose their priorities for what JCOM could or should become be writing to [readers@jcom.sissa.it]. Soon, we will open shared spaces for discussion. All of this, we hope, will lead to bright new ideas and to a new version of JCOM by spring 2014.

Luisa Massarani, Matteo Merzagora, Nico Pitrelli, Brian Trench, Bora Zivcovic

How TO CITE: L. Massarani, M. Merzagora, N. Pitrelli, B. Trench, B. Zivcovic, New directions for JCOM, JCOM 12(02) (2013) E. 